\title{
Large Papillomatous and Pedunculated Nevus Sebaceous
}

\author{
Taksaorn Ubol Kobkul Aunhachoke \\ Division of Dermatology, Department of Medicine, Phramongkutklao Hospital, \\ Bangkok, Thailand
}

\section{Key Words}

Adnexal hamartoma $\cdot$ Congenital $\cdot$ Blaschko's lines $\cdot$ Nevus sebaceous

\begin{abstract}
We present a 6-week-old female infant from the Lao People's Democratic Republic with a large, red, exophytic scalp mass and numerous flesh-colored verrucous plaques on her face and the right half of her body since birth. The clinical and pathological findings are consistent with the new phenotype of the large, polypoid types of nevus sebaceous.
\end{abstract}

(C) 2015 The Author(s)

Published by S. Karger AG, Basel

\section{Case Report}

A 6-week-old full-term female infant from the Lao People's Democratic Republic presented with a large, red, exophytic scalp mass and numerous flesh-colored verrucous plaques on her face and the right half of her body (trunk, legs, arm, palm and sole) since birth (fig. 1). Her mother noted that the lesions were tender upon putting her down on the lesion. Apart from the masses, she was otherwise healthy. She had no history of seizure, and her development was appropriate for her age. She was born to a healthy 35-year-old multigravida mother via spontaneous vaginal delivery with 3,000 g birthweight. There was neither family history of a similar skin lesion nor known genetic disorders in the family. There was no consanguineous marriage in the family, as shown in her pedigree (fig. 2).

A physical examination revealed multiple circumscribed skin-colored to yellowish, hairless, cerebriform plaques located on the right side of the scalp extending from the frontal to occipital area, face, trunk, and extremities. Most of the lesions were situated on the right side of the body, except for the plaques on the face that had bilateral symmetrical arrangement on both cheeks, forehead, and upper lip. Lesions on the trunk and extremities were less well- 
formed than those on the scalp and face. There was a large, soft, erythematous, hairless, cerebriform, pedunculated mass on top of the yellowish plaques on the occipital region of the scalp. Other physical examination was within normal limit.

The skin biopsy was done on 2 different lesions: the yellowish cerebriform plaque and the large, erythematous, cerebriform, pedunculated mass. Both sites revealed papillomatosis of the epidermis with enlarged sebaceous glands (fig. 3). Further imaging study showed no underlying cranial bone defect, with normal structure of the brain in a computed tomography scan. Other laboratory investigations, including complete blood count, blood chemistry, urine analysis, electrolytes, and thyroid function, were normal. Since the patient presented with large nevus sebaceous, we further assessed for musculoskeletal, neurologic, and ophthalmologic defects. All tests, including hearing test, visual test, and bone X-ray, were normal.

Her clinical and pathological findings were consistent with large papillomatous and pedunculated nevus sebaceous, a new variant of nevus sebaceous. For the treatment, we planned to perform surgical excision of the pedunculated mass on the occipital area; however, the patient's family declined further management.

\section{Discussion}

Nevus sebaceous of Jadassohn was first described in 1985 as a circumscribed hamartomatous lesion predominantly composed of sebaceous glands [1, 2]. Nevus sebaceous may present at multiple sites other than head and neck, or has atypical morphology. One rare morphological variant, namely cerebriform nevus sebaceous, was firstly reported by Ramesh et al. [3] in 1998, when they described a 20-year-old man with a large cerebriform plaque over the right parieto-occipital region, which was confirmed by histopathological examination. After that, there were reported cases with similar presentation in different areas [4-7].

In 2008, Correale et al. [8] reported 5 cases of a new variant of unusual presentation of nevus sebaceous describing it as large, papillomatous, and pedunculated nevus sebaceous. All of the patients presented at birth with large exophytic lesions. In all but one, the masses were confined to the scalp and face. Only one patient had extensive nevus sebaceous extending from the scalp to the elbow. None of the patients showed any associated abnormalities. In 2011, Lin et al. [9] reported a case of a 1-day-old full-term baby boy with a large tumor on the left parietal scalp at birth. Examination revealed a large soft, pedunculated, hairless, cerebriform tumor. The tumor arose from the central portion of a yellowish to orange-colored fusiform plaque oriented along Blaschko's lines. No underlying cranial bone defect was noted, and she was otherwise healthy. The clinical and pathological features of our case are consistent with this new phenotype of the large, polypoid types of nevus sebaceous.

Children born with large nevus sebaceous should be assessed for neurologic and ophthalmologic deficits. Widespread cutaneous nevus sebaceous (particularly those spreading over two or more dermatomes) may be a part of linear nevus sebaceous syndrome, which may encompass skeletal, ocular, and neurologic abnormalities. Other possible associated disorders are patent ductus arteriosus, aortic coarctation, horseshoe kidney, undescended testis, and hepatosplenomegaly [10].

Differential diagnoses are different distinct syndromes characterized by a large or multiple epidermal nevi, neurological defects, ocular abnormalities, and skeletal manifestations. These syndromes include CHILD syndrome, nevus sebaceous syndrome, and nevus comedonicus syndrome, which can be differentiated by the genetic and clinical presentation. 
Excision of the lesion may be considered at any age for cosmetic reasons. However, because of the potential of malignant transformation, some authors recommended prophylactic full-thickness complete excision of the lesion with minimum 2-3 mm margins, in the postpubertal period. Ablative laser and photodynamic therapy may be considered for inoperable lesions. Any new bump within a nevus sebaceous should be examined and biopsy considered [2].

\section{Acknowledgement}

The authors would like to acknowledge with deep appreciation and gratitude the invaluable help of Dr. Artit Nakakes, MD, who assisted in English language revision and completion of this paper.

\section{Statement of Ethics}

The parents of this patient gave written informed consent for this paper.

\section{Disclosure Statement}

The authors have no conflicts of interest to disclose.

\section{References}

1 Puri N: A clinical and histopathological study of nevus sebaceous. J Pak Assoc Dermatol 2014;24:31-33. Leung AKC, Barankin B: Nevus sebaceous. Austin J Pediatr 2014;1:1006.

-3 Ramesh A, Murugusundaram S, Vittel K, Kumar S, Janaki VR, Boopalraj JM: Cerebriform sebaceous nevus. Int J Dermatol 1997;37:220.

-4 Valerio E, Mardegan V, Zanella C, Gaio P, Cutrone M: Cerebriform nevus sebaceous in neonate. J Pediatr 2014;164:665-666.

5 Ganesh A, Priyanka G, Jerajani H: Cerebriform nevus sebaceous of Jadassohn. Indian Pediatr 2013;50:1072.

6 Mahajan R, Dogra S, Kanwar AJ, Saikia UN, Agrawal S: Extensive cerebriform nevus sebaceous: an unusual presentation. Dermatol Online J 2012;18:9.

7 Maheshwari V, Alam K, Prasad S, Sharma R, Khan AH, Sood P: Cerebriform nevus sebaceous: a rare entity. Dermatol Online J 2006;12:21.

-8 Correale D, Ringpfeil F, Rogers M: Large, papillomatous, pedunculated nevus sebaceous: a new phenotype. Pediatr Dermatol 2008;25:355-358.

-9 Lin HC, Lee JY, Shieh SJ, Hsu CK: Large, papillomatous and pedunculated nevus sebaceous. J Dermatol 2011;38:200-202.

10 Menascu S, Donner EJ: Linear nevus sebaceous syndrome: case reports and review of the literature. Pediatr Neurol 2008;38:207-210. 


\section{Case Reports in Dermatology}

Ubol and Aunhachoke: Large Papillomatous and Pedunculated Nevus Sebaceous
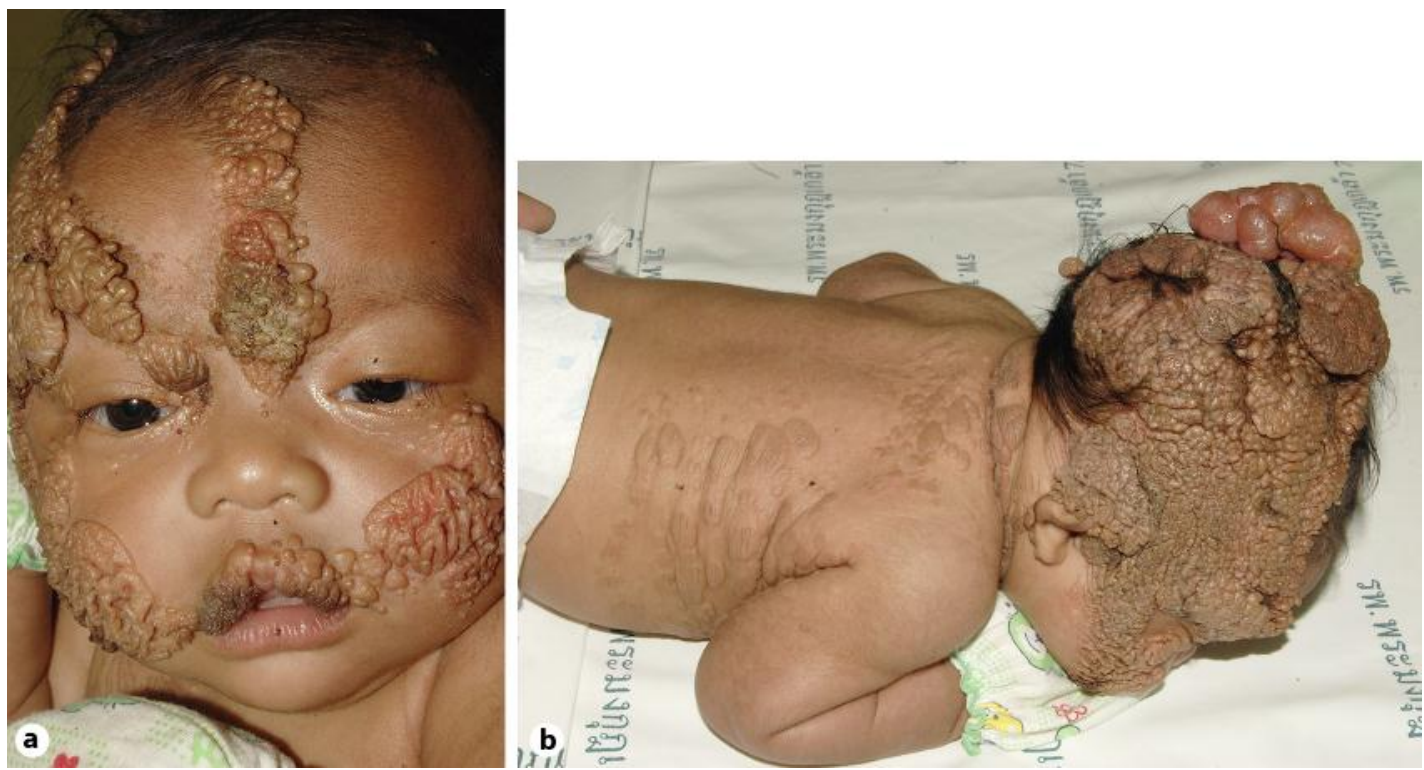

Fig. 1. a Bilateral symmetry yellowish, cerebriform plaques on both cheeks, forehead, and upper lip. b Multiple circumscribed skin-colored to yellowish, cerebriform plaques on the right side of the scalp and trunk together with a large, soft, erythematous, hairless, cerebriform, pedunculated mass on top of the yellowish plaques at the occipital region.

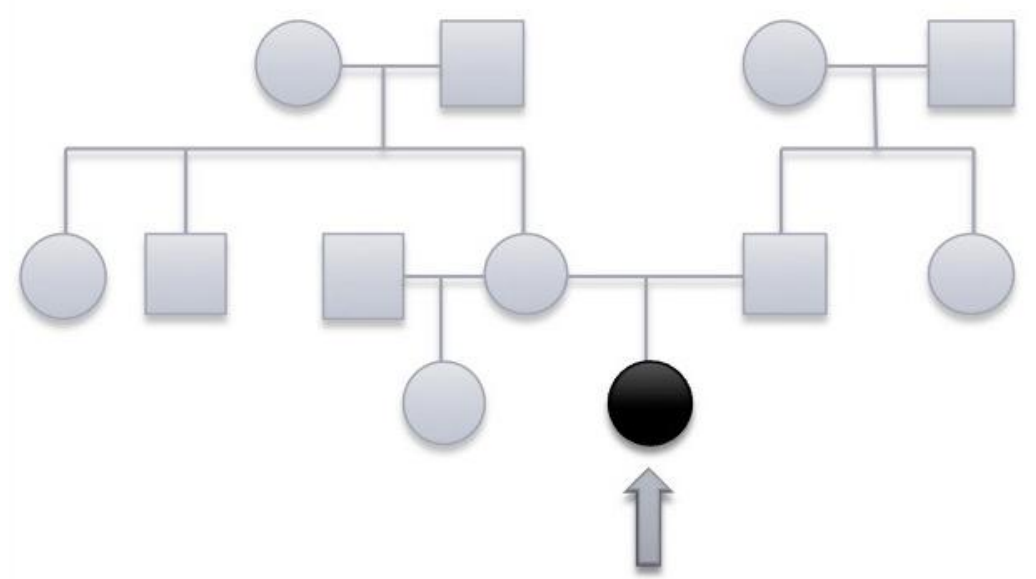

Fig. 2. Pedigree of the patient. 


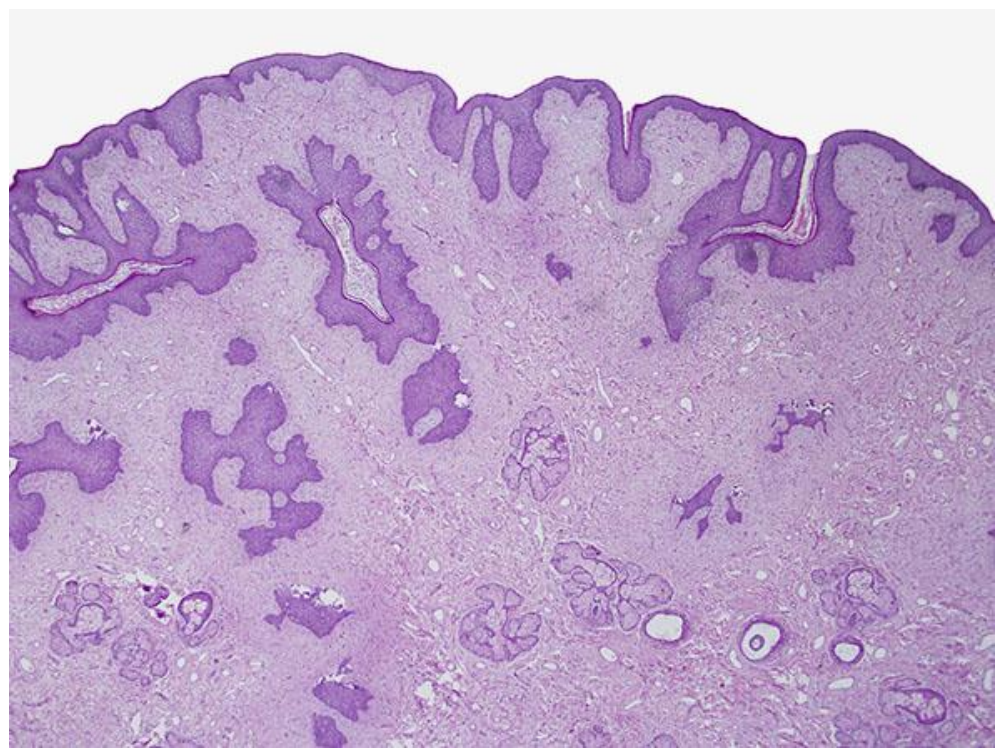

Fig. 3. Histopathological study showing papillomatosis of the epidermis with enlarged sebaceous glands. HE. $\times 4$. 